\title{
Myelin in Multiple Sclerosis Is Developmentally Immature
}

\author{
Mario A. Moscarello, D. Denise Wood, Cameron Ackerley, " and Christos Boulias \\ Division of Biochemistry Research and *Department of Pathology, Hospital for Sick Children, Toronto, Ontario, Canada M5G 1X8
}

\begin{abstract}
The etiology of multiple sclerosis (MS) is considered to involve genetic, environmental, infective, and immunological factors which affect the integrity of a normally assembled myelin sheath, either directly or indirectly resulting in demyelination. In a correlative study involving protein chemical, mass spectrometric, and electron microscopic techniques we have determined that myelin obtained from victims of MS is arrested at the level of the first growth spurt (within the first 6 yr of life) and is therefore developmentally immature. The data supporting this conclusion include $(a)$ the pattern of microheterogeneity of myelin basic protein (MBP); (b) the $\mathbf{N H}_{2}$-terminal acylation of the least cationic component of MBP ("C-8"); (c) the phase transition temperature $\left(T_{c}\right)$ of myelin isolated from victims of MS correlated with the increased proportion of the least cationic component of MBP; and $(d)$ immunogold electron microscopy using an antibody specific for "C-8" showed that the distribution of gold particles in a 2-yr-old infant was similar to the distribution found in a victim of MS. We postulate that this developmentally immature myelin is more susceptible to degradation by one or a combination of factors mentioned above, providing the initial antigenic material to the immune system. (J. Clin. Invest. 1994. 94:146-154.) Key Words: multiple sclerosis • demyelination • development $\cdot$ myelin basic protein • myelin
\end{abstract}

\section{Introduction}

Multiple sclerosis (MS) ${ }^{1}$ is a demyelinating disease of the human central nervous system. It is considered by some to be multifactorial in origin. An environmental factor (possibly a virus) induces disease in a genetically susceptible host, resulting in an autoimmune disease. Variations of this theme are presented in several review articles published recently (1-5). Whereas all theories assume that MS represents breakdown of a normally structured myelin sheath, studies in our laboratory suggest that MS occurs in a structurally immature myelin membrane. We have come to this conclusion from our studies of certain aspects of myelin basic protein (MBP), one of the major

Address all correspondence to M. A. Moscarello, Division of Biochemistry Research, Hospital for Sick Children, 555 University Avenue, Toronto, Ontario, Canada M5G 1X8.

Received for publication 22 September 1993 and in revised form 14 January 1994.

1. Abbreviations used in this paper: EAE, encephalomyelitis; MBP, myelin basic protein; MS, multiple sclerosis; $T_{c}$, transition temperature.

J. Clin. Invest.

(c) The American Society for Clinical Investigation, Inc. 0021-9738/94/07/0146/09 \$2.00

Volume 94 , July $1994,146-154$ proteins in myelin. Historically, MBP has been linked to MS because it induces allergic encephalomyelitis in laboratory animals, variously considered to be a model for MS. Although immunological studies on encephalomyelitis (EAE) are numerous, the detailed chemical structure of MBP, in particular its microheterogeneity, and the implications of the charge differences on the stability of the myelin sheath have been largely ignored, particularly as they relate to disease.

Myelin is the multilayered structure which surrounds the axons of the central and peripheral nervous systems. In the central nervous system (CNS) the myelin proteins account for $\sim 20$ $25 \%$ of the dry weight, the rest of which is contributed by the lipids. Two proteins, the MBPs and hydrophobic proteolipid types make up $\sim 85 \%$ of the total protein. Neither of these two groups represent a single species. In the human, MBP is known to consist of several isoforms. Four variants of molecular masses $21.5,20.2,18.5$, and $17.3 \mathrm{kD}$ have been identified in developing human spinal cord (6). At least three variants have been reported in the human brain, the 21.5-, 18.5-, and 17.3-kD sizes (7-11). These variants are believed to arise by alternate splicing of a single message.

In addition to size heterogeneity of MBP, charge microheterogeneity also exists, which has been documented only for the $18.5-\mathrm{kD}$ variant (the major variant in the human), although a similar charge microheterogeneity likely exists for the other variants as well (e.g., in the mouse) (12). The source of the charge microheterogeneity has been considered to arise, in part at least from phosphorylation, deamidation, and loss of $\mathrm{COOH}$ terminal arginine (13-15), oxidation of methionine to the sulfoxide (16), and recently, the presence of citrulline in the place of arginine at selected sites in the $\mathrm{NH}_{2}$ - and $\mathrm{COOH}$-terminal portions of the molecule (17).

When the $18.5-\mathrm{kD}$ variant of MBP is isolated and purified it migrates as a single band on SDS-PAGE. However, on alkaline disc gels in urea at $\mathrm{pH} 10.6$, the $18.5-\mathrm{kD}$ variant resolves into a variable number of proteins, usually 6-8. Each of these components differs from its nearest neighbor by one charge, hence the term charge microheterogeneity. Several of the charge isomers can be separated and purified on CM52 columns (17). The most cationic (considered the most unmodified) elutes last from the column and is called C-1 (13-15). Component 2, C-2, elutes just before $\mathrm{C}-1$ and differs from $\mathrm{C}-1$ by the loss of one positive charge and so on for the other components.

When purified MBP from adult brain is applied to a CM52 column at $\mathrm{pH} 10.6$, a variable amount, $\sim 20 \%$, fails to bind to the column and is obtained before the commencement of the salt gradient. From protein sequencing data we determined that six arginyl residues were replaced by citrulline, a known posttranslational modification of arginine (17). Since citrulline is neutral, this modification alone accounts for the loss of six positive charges from the molecule. Recent studies on the microheterogeneity of MBP during development in the rat yielded similar results to those found in the human and therefore it is unlikely that post mortem changes affected the relative amounts of " $\mathrm{C}-8$ "' in MBP (J. Ramwani and M. A. Moscarello, unpublished data). 
Our interest in " $\mathrm{C}-8$ " " was stimulated by earlier protein-lipid interaction studies in model systems (18). In liquid X-ray diffraction studies, C-1 induced the formation of "crystalline" multilayers; C-2 was $\sim 50 \%$ as effective as C-1; C-3 was $\sim 40 \%$ as effective as $\mathrm{C}-1$ and C-8 was not effective at all. Vesicle aggregation studies were in agreement with the $\mathrm{x}$-ray data i.e., although $\mathrm{C}-8$ bound to lipid vesicles containing acidic lipids, it was unable to aggregate or organize the lipid in a multilayer arrangement.

These data suggested that the different charge isomers may each have defined roles in the myelin multilayer structure and may be localized differently. Thus, when myelins of different densities were isolated from normal human white matter, the more dense, less compact myelin showed an increased amount of C-8 and a relative deficiency of C-1 (18), suggesting that the extent of myelin compaction was determined by the relative proportion of C-1. Since C-8 is the only MBP which contains citrulline, immunogold localization of C-8 in cryosections of human brain biopsies with a citrulline specific antibody, localized this particular charge isomer to the intraperiod line of myelin whereas antibody to the other charge isomers localized MBP to the major dense line (19).

In the present manuscript we report on studies which demonstrate that C-8 is relatively increased in MBP from victims of MS compared with MBP from normal white matter and MBP isolated from victims of other neurological diseases such as Alzheimer's, Parkinson's, amyotropic lateral sclerosis, motor neuron disease, and in the experimental allergic encephalomyelitis (EAE) animal model of MS. In fact the relative proportion of $\mathrm{C}-8$ in MBP from MS tissue was similar to that observed in a child of 3-4 yr of age. When correlated with other studies on the nature of the $\mathrm{NH}_{2}$-terminal blocking group and immunogold localization studies, we concluded that myelin development in MS is arrested at the level of a child less than $6 \mathrm{yr}$ old.

\section{Methods}

Source of human brain. Human brain white matter (both normal and diseased) was obtained from the Canadian Brain Tissue Bank (Toronto, Canada). Neuropathological diagnoses were provided to us with each sample of white matter in the case summary. The dissections of white matter were carefully done so that none of the plaque or peri-plaque tissues of the MS samples were included. All the work reported in the present study was done with normal-appearing white matter.

Isolation of human myelin. Myelin was isolated from human brain white matter by the method of Lowden et al. (20).

Isolation of charge isomers of MBP. Basic protein (MBP) was isolated from human brain white matter as described by Cheifetz et al. (16). The various components were isolated by a modification of the method of Chou et al. (15). Briefly the MBP was dissolved in a ureaglycine buffer at $\mathrm{pH} 9.6$ and applied to a CM52 cation exchange column equilibrated with the urea-glycine buffer at $\mathrm{pH} 10.6$ (17). The components were eluted as described in the original method with a sodium chloride gradient $(0-0.2 \mathrm{M})$. The fractions under each peak were pooled and desalted by dialysis against water. The components were dialyzed, lyophilized, and stored at $-20^{\circ} \mathrm{C}$. C-8 which was recovered in the void volume as two fractions C8-A and C8-B was further purified by HPLC as described by us recently (17) yielding two purified fractions C8-A and C8-B (C. Boulias and M. A. Moscarello, manuscript submitted for publication).

Characterization of components. SDS-PAGE was carried out by the method of Laemmli (21) and alkaline-urea disc gels at $\mathrm{pH} 10.6$ by the method of Martenson and Gaitonde (22). Amino acid analyses were done on a Water's Pico Tag Amino Acid Analyser after hydrolysis in $5.7 \mathrm{~N} \mathrm{HCl}$ for $24 \mathrm{~h}$.
Mass spectrometry. All fast atom bombardment (FAB) mass spectra were recorded using the VG-analytical-SE instrument equipped with Ion Tech Field ion gun (Visons, Manchester, England). The peptides were dissolved in water/methanol (1:1) or water/acetonitrile (1:1) and 1-2 $\mu \mathrm{l}$ of each were loaded on to a target containing $1 \mu \mathrm{l}$ thioglycerol/ glycerol (3:1) matrix and then were bombarded by Xenon atom ( $2 \mathrm{~mA}$ anode current, $10 \mathrm{kev}$ anode potential). The spectra were recorded using VG-11-250 data system as a continum data file (multichannel analysing mode) and 3-4 scans were accumulated. The resolution was set at 2,000 (10\% valley definition) and scanned from $\mathrm{m} / \mathrm{z} 2,800$ to 1,500 atomic mass units (amu) for peptides consisting of residues 1-21 of MBP. The mass values observed were the ${ }^{12} \mathrm{C}$ nominal mass values. The natural carbon 13 isotopic peaks were observed in this low resolution analysis. The average mass values were observed and reported.

Preparation of peptides for mass spectrometry. Peptides consisting of residues 1-21 of C-1 and C-8 were prepared by cyanogen bromide cleavage followed by purification on HPLC as described previously (23).

Electron microscopy. Human white matter was obtained from surgical biopsies from a 2-yr-old male, a 9-yr-old female, a 16-yr-old male and a 16-yr-old female. The white matter from a case of multiple sclerosis of $6 \mathrm{yr}$ duration was obtained at autopsy $4 \mathrm{~h}$ after death. All samples were cut into blocks of $0.5 \mathrm{~mm}^{3}$ and fixed in $2 \%$ paraformaldehyde in $0.1 \mathrm{M}$ phosphate buffer $\mathrm{pH} 7.4$ for $2-4 \mathrm{~h}$. The tissues were rinsed thoroughly in phosphate buffer and infused with sucrose for a minimum of $36 \mathrm{~h}$. The samples were attached to aluminum pins and frozen in freon 22 cooled with liquid nitrogen. Ultra thin cryosections were cut with a Reichert Jung Ultracut E with an FC 4 cryo attachment (Department of Pathology, Hospital for Sick Children, Toronto, Canada) and immunolabeled as previously described by Griffith (24) except that 3nm gold particles were conjugated to Fab fragments prepared from either goat anti-rabbit or goat anti-mouse IgG and used as secondary ligand. The samples were stabilized in methyl cellulose containing $0.1 \%$ osmium tetroxide and $0.2 \%$ uranyl acetate before viewing and photographing in the transmission electron microscope.

\section{Results}

The charge isomers of MBP from normal and diseased white matter. When MBP was resolved by CM52 column chromatography at $\mathrm{pH} 10.6$, the chromatograms obtained are shown in Fig. 1. These chromatograms represent typical patterns for MBP isolated from normal infant, adult, and MS white matter. By visual observation it is readily seen that the proportion of $\mathrm{C}-8$ (tubes 1-15) compared with C-1 (tubes 58-70) in the MS sample is much higher than in the normal. The number of samples studied in this manner are shown in Table I. There were 18 normals, 13 MS, 6 Alzheimer's, 2 each of amyotropic lateral sclerosis and Parkinson's, and 1 motor neuron disease. The relative proportions of the various components were obtained by summing the $\mathrm{OD}_{280}$ under each peak (Fig. 1). The percent C-8 in the normal samples and in other neurological diseases was between 15 and $20 \%$ of the total MBP with the majority of samples $\sim 18 \%$. The MS samples were noteworthy in that this MBP was $\sim 45 \%$ C-8 emphasizing the relative preponderance of C-8 in this material. None of the MS samples fell within the normal range of $18.2 \pm 5.9$ although two of the MBP samples contained 27 and $29 \%$ of C-8. Since these two samples were from patients with long standing disease (age at autopsy, 78 and 73 years, respectively, both of whom died of malignant disease), the C-8 values probably reflect a relatively mild form of the disease. The inclusion of these two cases in the 13 we have studied gives rise to the large standard deviation, reflecting the fact that MS is known to be highly variable from individual to individual. The ratio of $\mathrm{C}-8 / \mathrm{C}-1$ is also shown in Table $\mathrm{I}$. The MS material shows a threefold increase in this ratio.

The SDS-PAGE of C-8 and C-1 from both MS and normal 

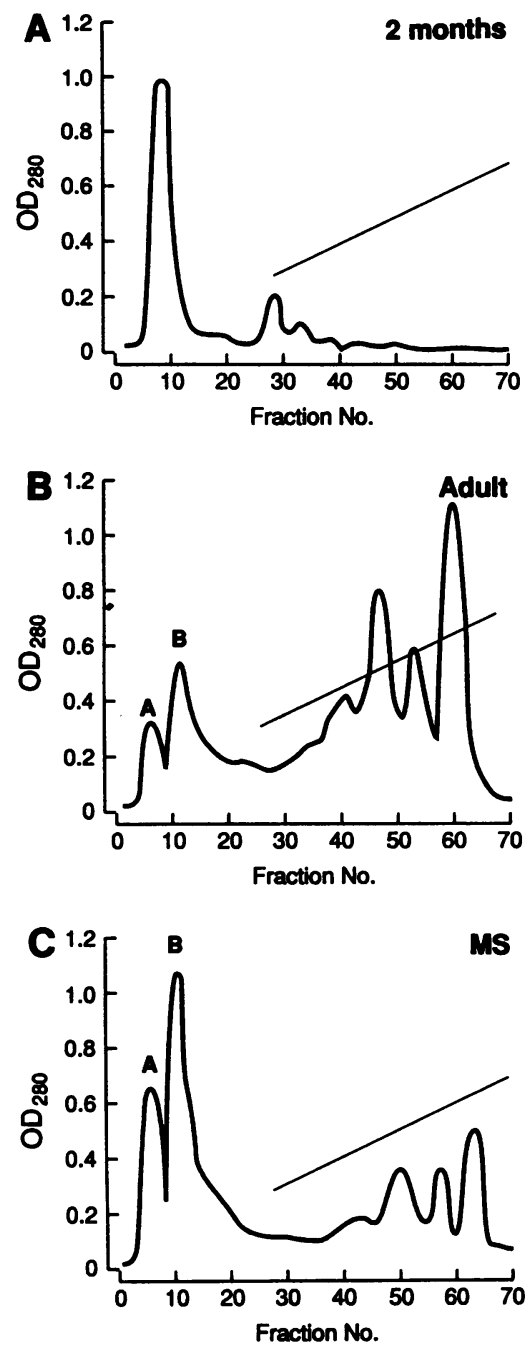

Figure 1. CM52 column chromatography of MBP isolated from normal and diseased white matter. (A) Fractionation of MBP from 2-mo infant. (B) Fractionation of MBP from a normal 46yr-old male who died of violent causes. $(C)$ Fractionation of MBP from a case of MS diagnosed 6 yr before death (46-yrold female).

white matter are shown in Fig. 2. Both C-8 and C-1 migrate with mobilities characteristic of the $18.5-\mathrm{kD}$ variant of MBP. C-8 from both normal and diseased tissues is more difficult to stain with Coomassie blue than $\mathrm{C}-1$ as seen by the less intense staining of C-8 (Fig. 2) even though approximately three times

Table I. Percent C-8 Recovered from CM52 Columns of Human $M B P$ and Ratio of C-8/C-1 from Same Columns

\begin{tabular}{lcccc}
\hline Sample & Age range & Percent "C-8" & “C-8”/C-1 & No. of samples \\
\hline N & $19-73$ & $18.2 \pm 5.8$ & $0.82 \pm 0.59$ & 18 \\
A & $66-73$ & $18.6 \pm 5.9$ & $0.79 \pm 0.27$ & 6 \\
LS & 43,64 & 17 & 0.50 & 2 \\
MN & 70 & 15 & 0.48 & 1 \\
P & 73,81 & 18 & 0.90 & 2 \\
MS & $40-65$ & $45.4 \pm 15$ & $2.45 \pm 0.5$ & 13 \\
\hline
\end{tabular}

For each CM52 column, $60-90 \mathrm{OD}_{280} \mathrm{U}$ of total protein was applied at pH 9.6 in urea-glycine buffer, washed with the same buffer and eluted with urea-glycine buffer, $\mathrm{pH} 10.6$, with a sodium chloride gradient from 0-0.2 M. The $\mathrm{OD}_{280}$ under each peak was determined and expressed as a percentage of the total $\mathrm{OD}_{280} . N$, normal; $A$, Alzheimer's disease; $M N$, motor neuron disease; $P$, Parkinson's disease; $M S$, multiple sclerosis; and $L S$, amyotropic lateral sclerosis.
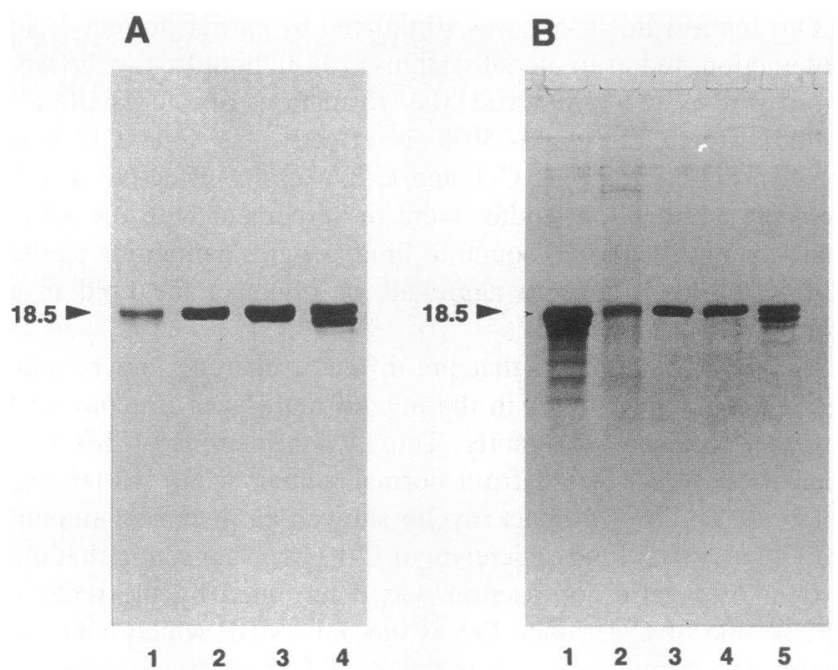

Figure 2. SDS-PAGE of major fractions isolated from CM52 columns of normal (adult) and MS MBP. (A) MBP from MS MBP. Lane 1, C8; lane 2, C-1; lane 3, C-2; lane 4, C-3. (B) MBP from normal white matter. Lane 1, starting material, i.e., MBP applied to CM52 column; lane 2, C-8; lane 3, C-1; lane 4, C-2; lane 5, C-3.

the amount of $\mathrm{C}-8$ was applied to the gel as $\mathrm{C}-1$. This is characteristic of all our C-8 preparations but cannot be explained at the moment. Although $\mathrm{C}-8, \mathrm{C}-1$, and $\mathrm{C}-2$ (Fig. $2 \mathrm{~A}$, lanes $1-3$ and $B$, lanes 2-4) migrate as single bands of $18.5 \mathrm{kD}, \mathrm{C}-3$ (Fig. $2 A$, lane 4 and $B$, lane 5) shows the $17-\mathrm{kD}$ variant of MBP also.

The overall similarity between C-8 from normal and MS white matter was confirmed by amino acid compositions (Table II). The values for $\mathrm{C}-1$ from normal material are taken from our published values (17). The amino acid composition of C-8 from MS material is almost identical to that for C-8 from normal white matter, including similar amounts of citrulline and ornithine. From these studies we concluded that $\mathrm{C}-8$ from normal MBP was the same as C-8 from MS MBP. When compared with $\mathrm{C}-1$, the most cationic of the components, the $\mathrm{C}-8$ compositions contained higher Glx, citrulline but lower arginine values which is typical of all our C-8 preparations (17).

Since the crude C-8 material consisted of C8-A and C8-B fractions, purification and identification of the proteins was established and reported in a separate communication (C. Boulias and M. A. Moscarello, manuscript submitted for publication). Briefly, each of C8-A and C8-B (Fig. 1) were further purified by HPLC and were shown to consist mainly of MBP-like proteins by immunoblotting with a monoclonal antibody which recognized residues $130-137$ of MBP, amino acid analyses and partial protein sequencing. The overall similarity between the C-8 compositions and C8-B can be seen in Table II. The C8B composition (also similar to C8-A) was reproduced from $\mathrm{C}$. Boulias and M. A. Moscarello.

When studied separately, it can be seen that both C8-A and C8-B fractions were increased in the MS material compared with normal (Table III). Since we have demonstrated that C8A was not recovered in isolated compact myelin (only C8-B is found), but was found in lesser compact forms of myelin isolated from white matter (C. Boulias and M. A. Moscarello, manuscript submitted for publication) the increased proportion found in MS samples was a reflection of greater amounts of less compact myelin in MS. 
Table II. Amino Acid Composition of C-8 from MBP Isolated from MS and Normal White Matter (Residues/100)

\begin{tabular}{lrcrr}
\hline \multicolumn{1}{c}{ Amino acid } & MS “C-8"* & N "C-8"* & N C-1 & \multicolumn{1}{c}{ C8-B" } \\
\hline Aspartic acid & $7.8 \pm 0.23$ & $7.3 \pm 0.64$ & 6.5 & $9.0 \pm 0.9$ \\
Threonine & $4.8 \pm 0.19$ & $5.4 \pm 0.26$ & 4.7 & $4.9 \pm 0.3$ \\
Serine & $9.3 \pm 0.22$ & $10.9 \pm 0.5$ & 11.2 & $12.1 \pm 1.4$ \\
Glutamic acid & $9.2 \pm 1.25$ & $8.0 \pm 0.58$ & 5.3 & $9.1 \pm 2.3$ \\
Proline & $7.7 \pm 0.51$ & $8.0 \pm 0.49$ & 7.1 & $7.3 \pm 1.5$ \\
Citrulline & $2.6 \pm 0.81$ & $3.9 \pm 0.7$ & - & $2.7 \pm 1.9$ \\
Glycine & $14.2 \pm 0.52$ & $16.4 \pm 0.61$ & 15.3 & $17.9 \pm 3.3$ \\
Alanine & $8.2 \pm 0.43$ & $7.9 \pm 0.43$ & 7.1 & $8.8 \pm 1.1$ \\
Valine & $2.2 \pm 0.42$ & $2.2 \pm 0.18$ & 2.4 & $3.0 \pm 0.8$ \\
Methionine & $1.1 \pm 0.08$ & $0.8 \pm 0.38$ & 1.2 & $1.1 \pm 0.5$ \\
Isoleucine & $1.9 \pm 0.12$ & $2.1 \pm 0.18$ & 2.4 & $1.8 \pm 0.7$ \\
Leucine & $4.6 \pm 0.34$ & $4.9 \pm 0.33$ & 4.7 & $2.4 \pm 1.6$ \\
Tyrosine & $2.0 \pm 0.14$ & $2.4 \pm 0.14$ & 2.4 & $2.0 \pm 0.7$ \\
Phenylalanine & $4.5 \pm 0.39$ & $4.9 \pm 0.36$ & 5.3 & $3.8 \pm 0.4$ \\
Ornithine & $1.0 \pm 0.78$ & $1.4 \pm 0.54$ & - & $0.3 \pm 0.1$ \\
Lysine & $8.4 \pm 0.68$ & $6.3 \pm 0.78$ & 7.1 & $4.8 \pm 0.8$ \\
Histidine & $4.8 \pm 0.20$ & $6.0 \pm 0.45$ & 5.9 & $6.4 \pm 0.9$ \\
Arginine & $5.6 \pm 1.00$ & $6.9 \pm 0.68$ & 11.2 & $7.9 \pm 2.2$ \\
\end{tabular}

Each sample was hydrolyzed in $5.7 \mathrm{~N} \mathrm{HCl}$ at $100^{\circ} \mathrm{C}$ in gas phase for $24 \mathrm{~h}$. After removal of $\mathrm{HCl}$, the hydrolysate was derivatized and separated on a Water's Pico Tag System. All samples were HPLC purified before analysis. * Mean and standard deviation of four independent amino acid analyses. ${ }^{\ddagger}$ Mean and standard deviation of five independent amino acid analyses. ${ }^{8}$ Taken from the published values for $\mathrm{C}-1$ (17).

Charge isomers of MBP isolated from human white matter at various ages. MBP was isolated from white matter of human brains of various ages (in the case of the 5-d-old infant whole brain was used). The CM52 columns were run as described in Methods. By 5 yr of age most of the material bound to the column and was resolved into several components. The relative proportion of C-8 in all samples is collected in Fig. 3. Up to the age of two years all the MBP $(100 \%)$ chromatographed as C-8. None of the other components were eluted with the sodium chloride gradient. Between the ages of 2 and $4 \mathrm{yr}$, a dramatic decrease in the percent of C-8 was observed and the adult level of $\sim 20 \%$ was attained which decreased only slightly from 4 to $16 \mathrm{yr}$. Also shown in Fig. 3 is the transition temperature $\left(T_{c}\right)$ of myelin isolated from white matter of children of various ages (reproduced from the data of Chia et al. [25]). The increase in $\mathrm{T}_{\mathrm{c}}$ suggested an increased order of the membrane, which correlated with a decreased proportion of C-8 in MBP and with an increase in the proportion of $\mathrm{C}-1$. The $\mathrm{T}_{\mathrm{c}}$ values for six myelin samples $\left(40^{\circ} \mathrm{C}\right)$ isolated from victims of $\mathrm{MS}$ are also reproduced

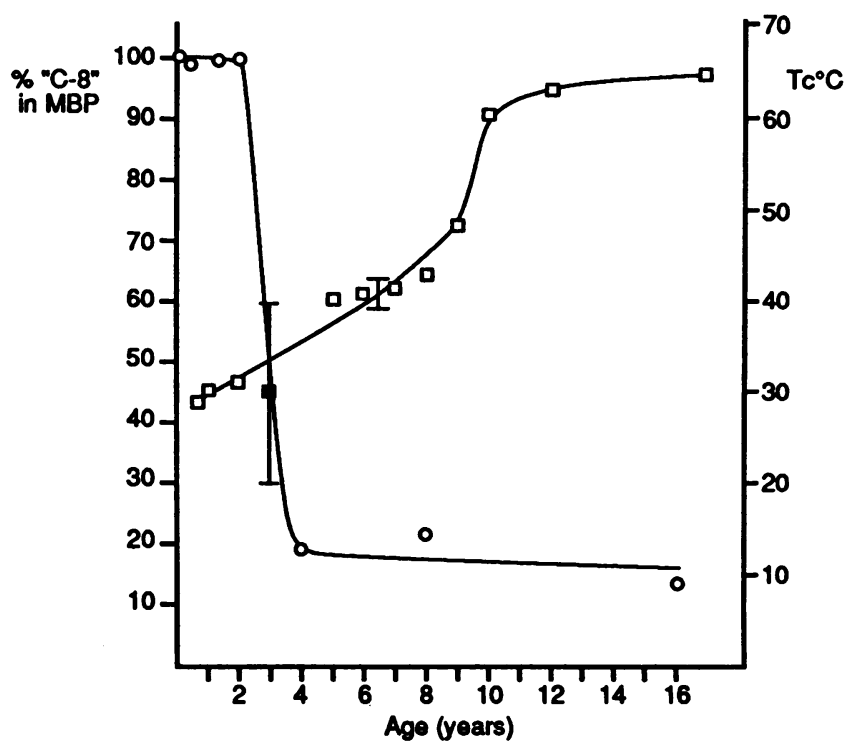

Figure 3. The relative proportions of C-8 in MBP obtained from CM52 column chromatography. The percentage of C-8 is plotted for different ages. Superimposed on these data are the transition temperatures obtained for isolated myelin at different ages (taken for an earlier $\mathrm{x}$-ray diffraction study by Chia et al. (24). ( $\square$ ) percent C-8 in MBP from victims of MS; $(\square)$ the transition temperature $\left(T_{c}\right)$ of myelin isolated from victims of MS.

here (26), shown as a bar in Fig. 3. The bar representing the $\mathrm{T}_{\mathrm{c}}$ values for myelin from MS material at $\sim 40^{\circ} \mathrm{C}$, overlaps with the upper limit of the bar showing the range of values for percent of C-8 in MBP. Both parameters reflect the lack of maturity of myelin in MS, i.e., the $T_{c}$ suggests myelin from a 6-7-yr-old child while the percent of C-8 suggests membrane from a 3-4 year old. Therefore, both the relative amounts of C-8 as well as the order of the membrane in MS fall in the range of these parameters in developing myelin during the first growth spurt (i.e., within the first six years).

The $\mathrm{NH}_{2}$-terminal acylation of $\mathrm{C}-8$ from $\mathrm{MS}$ victims is similar to that of infants. During our studies on the nature of the $\mathrm{NH}_{2}$ terminal acylation of myelin basic protein, we observed that both C-1 and C-8 were heterogeneously acylated with alkyl carboxylates 2-10 carbons long (23), in contrast to the original studies which reported the $\mathrm{NH}_{2}$-terminus of MBP was acetylated only $(27,28)$. In addition, we showed that the relative abundance of the alkyl carboxylates differed for C-1 and C-8.

To study the $\mathrm{NH}_{2}$-terminal acylation of $\mathrm{C}-1$ and $\mathrm{C}-8$ from MBPs isolated from infants, normal adults, and adults with various neurological diseases, we prepared the $\mathrm{NH}_{2}$-terminal peptide 1-21 from each protein by cyanogen bromide cleavage as described previously (23). Each peptide was subjected to

Table III. Relative Proportions of Charge Isomers Isolated from Normal and Multiple Sclerosis White Matter

\begin{tabular}{crrrrr}
\hline & \multicolumn{5}{c}{ Charge isomers } \\
\cline { 2 - 6 } Source of white matter & \multicolumn{1}{c}{ C8-A } & \multicolumn{1}{c}{ C8-B } & C3 & C2 & C1 \\
\hline Normal* & $10.18 \pm 2.49$ & $10.8 \pm 5.56$ & $15.45 \pm 5.21$ & $11.05 \pm 1.35$ & $17.42 \pm 4.62$ \\
MS $^{\ddagger}$ & $16.57 \pm 1.27$ & $18.04 \pm 3.96$ & $12.63 \pm 2.11$ & $9.07 \pm 0.27$ & $14.25 \pm 1.49$ \\
\end{tabular}

\footnotetext{
* The mean and standard deviation from five different normal individuals. ${ }^{\ddagger}$ The mean and standard deviation from four different MS victims.
} 
Table IV. Relative Abundance of Alkyl Carboxylates at $\mathrm{NH}_{2}$ Terminus of Components 1 and 8 of Myelin Basic Protein Isolated from Normal and Diseased White Matter

\begin{tabular}{|c|c|c|c|c|c|c|}
\hline \multirow[b]{2}{*}{$\begin{array}{c}\text { Component } \\
\text { of MBP }\end{array}$} & \multirow[b]{2}{*}{ Neurological status } & \multicolumn{5}{|c|}{$\mathrm{NH}_{2}$-terminal alkyl carboxylate } \\
\hline & & $\begin{array}{l}\text { Acetyl } \\
\text { (C2) }\end{array}$ & $\begin{array}{l}\text { Butyl } \\
\text { (C4) }\end{array}$ & $\begin{array}{l}\text { Hexyl } \\
\text { (C6) }\end{array}$ & $\begin{array}{l}\text { Oxtyl } \\
\text { (C8) }\end{array}$ & $\begin{array}{l}\text { Decyl } \\
\text { (C10) }\end{array}$ \\
\hline & & & & $\%$ & & \\
\hline \multirow[t]{6}{*}{ C-1 } & Normal* & 18 & 28 & 30 & 15 & 8 \\
\hline & Motor neuron disease & 12 & 23 & 28 & 20 & 8 \\
\hline & Parkinson's & 13 & 28 & 28 & 19 & 9 \\
\hline & Huntington's & 12 & 25 & 31 & 21 & 11 \\
\hline & Multiple sclerosis (127) & 15 & 29 & 31 & 25 & 8 \\
\hline & Multiple sclerosis (128) & 15 & 30 & 37 & 18 & - \\
\hline \multirow[t]{8}{*}{$\mathrm{C}-8$} & Normal (adult)* & 11 & 31 & 32 & 23 & 5 \\
\hline & (15 mos) & 45 & 32 & 22 & ND & ND \\
\hline & $(5 \mathrm{yr})$ & 56 & 35 & 8 & ND & ND \\
\hline & $(5 \mathrm{yr})$ & 42 & 38 & 20 & ND & ND \\
\hline & Multiple sclerosis (127) & 65 & 30 & ND & ND & ND \\
\hline & $" \quad " \quad$ (123) & 63 & 32 & ND & ND & ND \\
\hline & $" \quad(124)$ & 48 & 36 & 4 & ND & ND \\
\hline & " (128) & 60 & 40 & ND & ND & ND \\
\hline
\end{tabular}

Each protein was purified on HPLC as described earlier (17) and cleaved with cyanogen bromide (23). Peptide 1-21 was isolated by HPLC and identified by amino acid analysis. * Mean of five determinations. Variation $\pm 3 \%$. ND, not detected.

FAB mass spectrometry. The relative abundance of the various alkyl carboxylates is shown in Table IV. It can be seen for peptide 1-21 from C-1 that the relative abundance of all of the alkyl carboxylates fall within a narrow range for each of acetyl, butyl, hexyl, octyl, and decyl species. On the other hand, the alkyl carboxylates on the various $\mathrm{C}$-8-derived peptides varied considerably. The normal adult contained all species of alkyl carboxylates similar to C-1 except that the acetyl was lower (11\%) and the octyl was higher (23\%). The 15-mo-old infant showed a high amount of acetyl (45\%), some butyl and hexyl but no octyl or decyl. The two 5-yr-old children showed similar patterns. The multiple sclerosis samples showed a high amount of acetyl (48-65\%), some butyl but none of the hexyl, octyl and decyl species (except MS, 124 which had 4\% hexyl). The MS samples were more like the infant samples and very different from the normal adults.

Immunogold labeling of cryosections of normal infant, adult and MS derived white matters. Cryosections were prepared from biopsy samples obtained from 2, 9, and 16-yr-old children and an MS sample obtained shortly after death. Sections were labeled with two antibodies, the anti-citrulline antibody which reacts only with C-8 and not any of the other components of MBP (29) and a monoclonal antibody directed against residues 130-137 of MBP. Labeling with 3-nm gold particles conjugated to Fab fragments of the secondary antibody was carried out as described in Methods. The electron micrographs are shown in Fig. 4. In Fig. 4, $A$ and $B$ are shown the labeling of cryosections from 2-yr-old infant. The anti-citrulline antibody (Fig. $4 A$ ) labeled these sections much more heavily than the anti-MBP antibody (Fig. $4 \mathrm{~B}$ ). In the 9-yr-old child, the labeling with the anti-MBP antibody was slightly heavier $(D)$ than with the anticitrulline antibody $(C)$. The 16 -yr-old child showed a distribution similar to the adult in which the anti-MBP antibody labeled the cryosections more heavily than the anti-citrulline antibody (Fig. 4, $E$ and $F$, respectively). The labeling of the cryosections from white matter of an MS victim showed heavy labeling with the anti-citrulline antibody and light labeling with the anti-MBP (Fig. 4, $G$ and $H$, respectively) similar to the labeling pattern of the cryosections from the 2-yr-old (Fig. 4, $A$ and $B$, respectively). To avoid bias due to selection of electron micrographs the number of particles $/ \mu \mathrm{m}^{2}$ of myelin were computed and are collected in Table V. With the anti-citrulline antibody, the number of particles $/ \mu \mathrm{m}^{2}$ decreased with increasing age from $34 \pm 4.4$ $\rightarrow 20 \pm 4.6$ for the 2- and 16-yr-old children, respectively. However, the MS sample contained $37 \pm 4.2$ particles $/ \mu \mathrm{m}^{2}$, similar to the number of particles found in the cryosections from the 2-yr-old. With the anti-MBP antibody, the number of particles/ $\mu \mathrm{m}^{2}$ increased from $21 \pm 2.9$ in the 2 -yr-old to $48 \pm 3.7$ in the 16-yr-old. The number of particles recorded in the MS samples was $18 \pm 2.8$ again similar to the number in the 2 -yr-old infant.

At first glance, the labeling pattern in Figs. 4, $A$ and $B$ may appear anomalous since the anti-MBP antibody should label all charge isomers of MBP to the same extent. However, differential reactivity between $\mathrm{C}-8$ and $\mathrm{C}-1$ has been observed. In Fig. $5 A$ is shown the SDS gel of MBP isolated from white matter of a 15-mo-old infant (lane $a$ ) compared with that from MBP (component 1 or $\mathrm{C}-1$ ) isolated from adult white matter (lane $b$ ). The infant MBP migrated with a slightly larger $M_{\mathrm{r}}$ than C-1 $(18.5 \mathrm{kD})$. We believe the slightly greater $M_{\mathrm{r}}$ of the 15 -mo-old MBP is due to posttranslational modifications although this is unproved. Although the amounts applied to the SDS gel appear equivalent for the two samples, three times more MBP was applied in the case of the 15-mo sample. We have consistently found that the C-8's from all sources react less with Coomassie blue than the other charge isomers. The immunoblots using the monocolocal antibody reactive with 130-137 of the MBP sequence showed much greater reactivity with $C-1$ (Fig. $5 B$, lane $b$ ) compared to MBP from the 15-mo-old infant (Fig. $5 B$, lane $a$ ) even though three times more protein was used in the case of the 15-mo-old sample (as measured by amino acid analyses). This markedly decreased reactivity was attributed to the presence of citrulline at position 130 in infant sample. The reactivity of these two MBPs with the anti-citrulline antibody is shown in Fig. $5 C$. The sample from the 15-mo-old infant reacted well with the antibody (Fig. $5 C$, lane $a$ ) while the adult form (C-1) failed to react (Fig. $5 C$, lane $b$ ) which is in accord with previous observations.

Since the 15-mo infant MBP consists entirely of C-8 (citrulline containing MBP) and contains none of the other charge isomers of MBP the immunogold data in Figs. $4, A$ and $B$ are explained by the poor reactivity of this material with the monoclonal antibody reactive with residues $130-137$. Other factors such as accessibility of the epitope (residues 130-137) and the dominant proportion of alkyl carboxylates with short carbon chains (i.e., acetyl and butyl) which may also affect the reactivity of the primary antibody are under investigation.

\section{Discussion}

Several lines of evidence have been presented which suggest strongly that myelin (or white matter) obtained from victims of multiple sclerosis is developmentally immature. The different techniques, isolation of charge isomers, $x$-ray diffraction, electron microscopy, and mass spectrometry do not agree on the exact developmental age. However, it must be in the first $6 \mathrm{yr}$ of life, i.e., one of the two periods of active myelination (the second active period is during adolescence) (1). Despite the fact that, some variability in the human samples can be expected, 

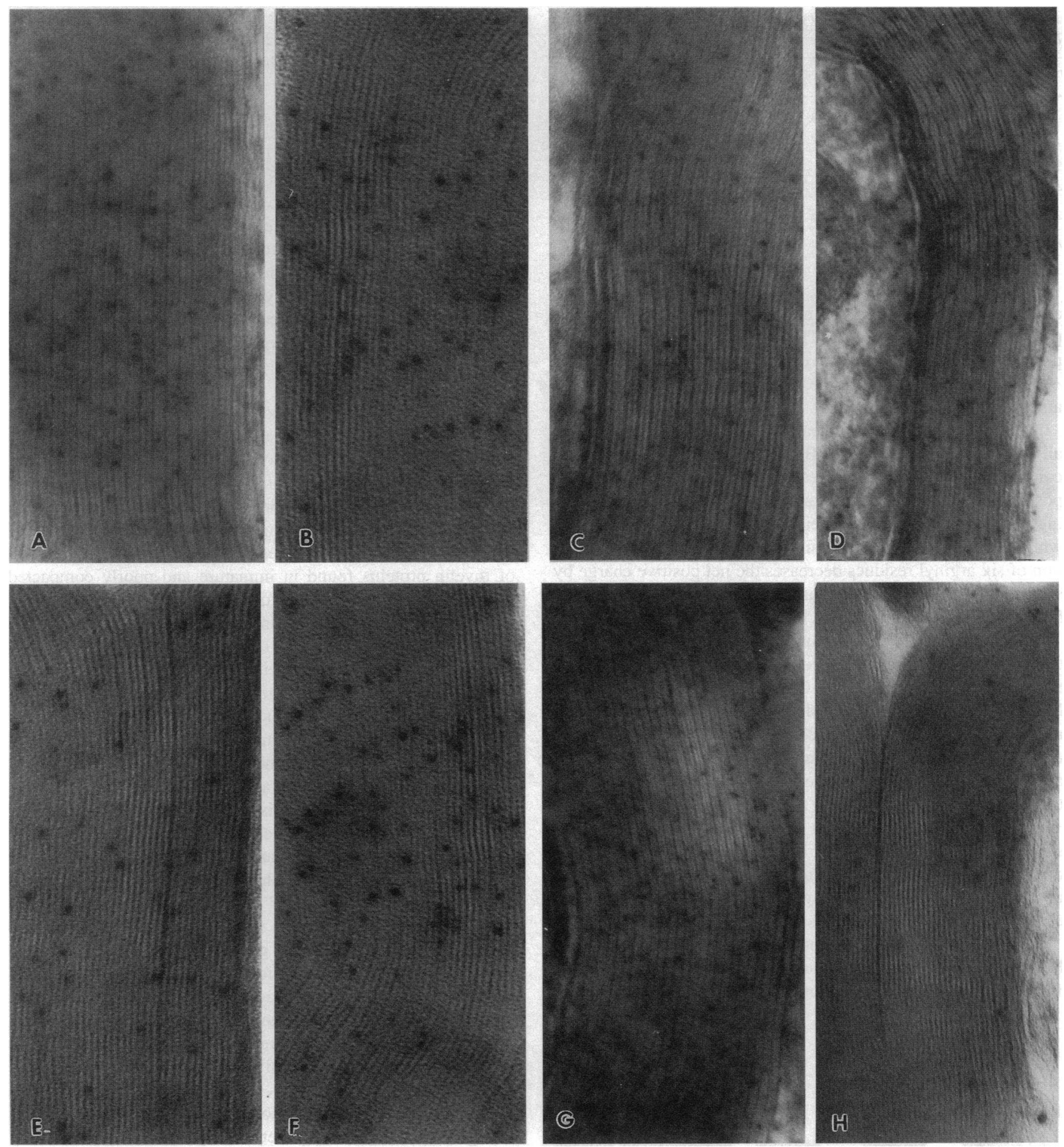

Figure 4. Immunogold labeling of cryosections of human white matter, biopsy samples. All sections were labeled with 3-nm gold particles conjugated to Fab fragments of the secondary antibodies, either anti-rabbit or anti-mouse. The primary antibody in all cases was either a monoclonal antibody directed at residues 130-137 of MBP or the anti-citrulline antibody, specific for C-8. ( $A$ and $B$ ) Cryosections from 2-yr-old infant labeled with anticitrulline $(A)$; anti-MBP $(B)$ antibodies. $(C$ and $D)$ Cryosections from 9-yr-old child labeled with anti-citrulline $(C)$; anti-MBP $(D)$ antibodies. $(E$ and $F$ ) Cryosections from 16-yr-old labeled with anti-citrulline $(E)$; anti-MBP $(F)$ antibodies. ( $G$ and $H$ ) Cryosections from 45 -yr-old MS victim labeled with anti-citrulline $(G)$; anti-MBP $(H)$ antibodies.

correlating the structure of myelin in victims of MS with the structure of myelin during the first growth spurt is highly significant.

The fractionation of MBP into its various components or charge isomers has elucidated some interesting phenomena. Thus the relative amounts of C-8 in MBP isolated from normal human white matter represents $\sim 20 \%$ of the total MBP. Since similar relative proportions of $\mathrm{C}-8$ were found in the rat (unpublished data) it is unlikely that post mortem changes in the human have a significant effect on the relative amounts of $\mathrm{C}-8$ in the isolated MBP. In addition, the relative amount does not change in other neurological diseases such as Alzheimer's, Parkinson's, 
Table V. Immunogold-labeled Cryosections of Human White Matter (particles/ $\mathrm{um}^{2}$ )

\begin{tabular}{ccccc}
\hline Age & Anti-citrulline Ab & $\mathrm{n}$ & Anti MBP Ab & $\mathrm{n}$ \\
\hline $2(\mathrm{~N})$ & $34 \pm 4.4$ & 58 & $21 \pm 2.9$ & 52 \\
$9(\mathrm{~N})$ & $31 \pm 4.9$ & 47 & $39 \pm 2.3$ & 56 \\
$16(\mathrm{~N})$ & $20 \pm 4.6$ & 53 & $48 \pm 3.7$ & 67 \\
45 (MS) & $37 \pm 4.2$ & 20 & $18 \pm 2.8$ & 18
\end{tabular}

$n$, Number of fields counted.

amyotropic lateral sclerosis, or motor neuron disease when compared with normals (Table I). The samples isolated from multiple sclerosis white matter were different in that C-8 represented $\sim 45 \%$ of the total MBP, i.e. a 2-3-fold increase over the amount found in normal MBP.

In our studies on the chemical differences between C-8 and all other charge isomers of MBP it was the only one found to contain citrullinyl residues instead of arginyl residues at selected positions in the molecule, determined by direct protein sequencing analysis (17). Since the ureido group of citrulline is neutral while the guanidino group of arginine is positive, the deimination of six arginyl residues decreases the net positive charge by six and accounts (in part at least) for the chromatographic behavior of C-8 on CM52 cation exchangers.

Mass spectrometric analyses have demonstrated that the $\mathrm{NH}_{2}$ terminus of MBP cannot be accounted for simply by acetylation as originally believed $(27,28)$. Our studies have shown that the $\mathrm{NH}_{2}$-terminus is heterogeneously acylated with alkyl carboxylates varying in length from 2-10 carbon atoms, with the 4 and 6 carbon species representing the major ones. Whereas the acetylated species of $\mathrm{C}-8$ in the adult accounted for $\sim 11 \%$ of the total, that from 15-mo and 5-yr-old children accounted for $\sim 50 \%$ of the total. Although both of these latter contained some 4 and 6 carbon alkyl carboxylates, none of the 8 or 10 carbon species were found. Similar mass spectrometric studies of C-8 from victims of MS showed similar distribution of alkyl carboxylates as the children's samples.

During development in the human the proportion of C-8 in MBP changed dramatically. Thus up to the age of $2 \mathrm{yr}$, virtually $100 \%$ of the MBP was accounted for by C-8. C-1 was not

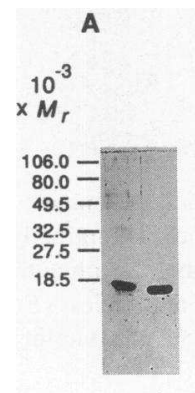

a b
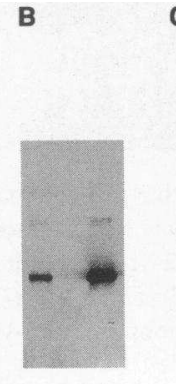

C

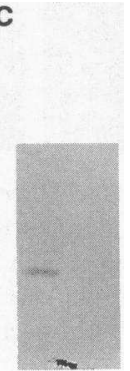

a b
Figure 5. Western blots of MBP from 15-mo infant compared with adult. $(A)$ Coomassie blue-stained gel showing MBP isolated from CM52 column after application of MBP from 15-mo sample. All MBP was recovered in the $\mathrm{C}$ 8 fraction. $9 \mu \mathrm{g}$ were applied to gel (lane $a$ ) compared with $3 \mu \mathrm{g}$ applied in lane $b$. The $\mathrm{C}-8$ fraction consistently stains poorly with Coomassie blue compared with other charge isomers. $(B)$ Immunoblot showing reactivity of 15-mo-old and adult forms of MBP with monoclonal antibody directed at residues $130-137$. The much greater reactivity of the adult form (lane $b$ ) is evident. (C) Immunoblot showing reactivity of 15-mo-old and adult forms of MBP with the anti-citrulline antibody. Only the 15-mo sample (lane $a$ ) reacted. detected at this time. From the age of $4 \mathrm{yr}$, the adult proportion of C-8 was obtained i.e., $\sim 20 \%$. These studies suggest that the $\mathrm{C}-8$ charge isomer is synthesized first during development, followed by $\mathrm{C}-1$ and the other components. It also rules out the possibility that $\mathrm{C}-8$ arose by a posttranslational modification of $\mathrm{C}-1$ since if this were the case some $\mathrm{C}-1$ should be found at all times. The possibility that $\mathrm{C}-1$ can arise from $\mathrm{C}-8$ is unlikely since no mechanism is known by which citrulline (found only in $\mathrm{C}-8$ ) in peptide bond can be converted to arginine in peptide bond. On the other hand, the deimination of arginine by a peptidyl arginine deiminase has been demonstrated (30). However, if $\mathrm{C}-1$ gave rise to $\mathrm{C}-8$ by this mechanism, significant amounts of $\mathrm{C}-1$ should be found early in development unless a very active deiminase is present in early development which converts all C-1 $\rightarrow$ C-8. Since this explanation is unlikely these data suggest that $\mathrm{C}-8$ and $\mathrm{C}-1$ arise by independent mechanisms in the human.

Further support for this hypothesis comes from studies with the MBP isolated from the brains of the mouse mutant Jimpy. Only an MBP with the mobility of C-8 was found in the Jimpy mutant material whereas all components were found in the MBP isolated from normal mouse brain of the same age (31). These studies suggest that interference with the normal process of myelination and compaction results in the continued production of myelin proteins found in immature and poorly compacted myelin. Thus, C- 8 continues to be produced in the absence of further myelin development. In an earlier study on the effects of starvation in the rat, it was reported that myelin synthesized in the malnourished rat had a protein composition characteristic of a normal rat of a younger age (32). Unfortunately, the microheterogeneity of MBP was not studied at that time.

In an extensive study of the myelin lipids during development in the human, Svennerholm and Vanier $(33,34)$ demonstrated that the adult lipid levels were attained by $\sim 2$ yr of age. Therefore, the changes in $T_{c}$ after this age, i.e., the dramatic increase, could not be accounted for by changes in lipid composition. On the other hand, the large decrease in proportion of C-8 followed by the appearance of $\mathrm{C}-1$, which has been shown to induce the formation of "crystalline" multilayer arrangement in lipid vesicles (35) readily accounts for the increase in order of the membrane in the 5-12-yr age group.

An electron microscopic study of immunogold (3-nm gold particles conjugated to Fab fragments) labeled cryosections of biopsies of human white matter demonstrated that the myelin of a 2-yr-old infant labels more heavily with the anti-citrulline antibody (which recognizes only C-8) than with anti-MBP antibody directed at residues 130-137 of MBP. Because this antibody reacts with $\mathrm{C}-8$ much more poorly than with component 1 (Fig. $5 B$ ), the labeling pattern in Fig. 4, $A$ and $B$ is entirely expected. This diminished reactivity to $C-8$ is explained by the deimination of the arginyl residue at position 130 in C-8. With the decreasing relative proportions of $\mathrm{C}-8$ in the 9- and 16-yrold samples, the labeling pattern reflects the relative decrease of $\mathrm{C}-8$ and increase of $\mathrm{C}-1$ in the maturing myelin sheath. Interestingly, the labeling of the MS sample ( 45 yr old) is similar to that of the 2-yr-old sample. Particle counting (Table V) confirmed these conclusions. In addition, the increased reactivity of C-8 from MS samples compared to C-8 from normal white matter has been documented but unexplained (29) and may contribute to the heavy labeling seen with the anti-citrulline antibody.

Experimental allergic encephalomyelitis (EAE) is considered to be the animal model of MS. EAE was induced in the SJL/J 
mouse by injection of bovine MBP (Mastronardi F. G., SimonsJohnson R., Ackerley C., Roots B. I., and M. A. Moscarello. manuscript in preparation). Since only a small amount of MBP could be obtained from each 3-mo-old mouse, it was not possible to study the microheterogeneity by CM52 column chromatography as we have done for the human MBP. Instead we used the urea-alkaline polyacrylamide gel electrophoresis method which resolves the various charge isomers in a similar manner, i.e., $\mathrm{C}-1$, the most cationic component, elutes last from the CM52 column and migrates with the greatest mobility in the urea-alkaline gel system. C-8 does not bind to the CM52 column at $\mathrm{pH} 10.6$, but migrates only a short distance into the polyacrylamide gel. Because the gel system is an analytical system, the resolution of the various components of MBP is more complete than that obtained with the preparative CM52 column method. Using the polyacrylamide gel system we found that the MBP from mice which developed EAE was identical to that isolated from normal mice. Each of the MBP samples was subjected to the vesicle aggregation assay, which is very sensitive to the net charge on the protein. All MBP samples showed identical vesicle aggregation patterns which confirmed in a quantitative assay the conclusions from the urea-alkaline gels in which all samples showed identical patterns of microheterogeneity. We concluded from these data that the microheterogeneity of MBP was not altered in EAE. Furthermore the EAE studies support a conclusion that changes in MBP in MS are primary and not secondary to the disease process.

From our studies we propose that the myelin sheath in multiple sclerosis is developmentally immature largely because of the continued synthesis of $\mathrm{C}-8$ at high levels and the failure to synthesize sufficient quantities of $\mathrm{C}-1$, thereby preventing the assembly of highly structured myelin. We postulate that signals (as yet undetermined) are transmitted from the compact myelin sheath to the oligodendrocyte which directs the cell to produce less C-8 and more C- 1 .

In a recent review of the pathogenesis of MS, Poser (39) concludes that myelinoclosia is a late event caused by unknown mechanisms. Our studies suggest that myelin breakdown resulting from the assembly of an unstable membrane represents an early event which need only occur to a small extent to initiate the subsequent sequelae of the immunological attack. This mechanism addresses the initial event whereby a myelin antigen is made available to the immune system. With the recent report of the larger MBP gene (36), interesting studies on transcriptional factors (37) and the possibility that multiple interacting genes may determine susceptibility in MS (38) investigations of gene regulation which determine post translational events may be rewarding in elucidating the chemical pathogenesis of MS.

\section{Acknowledgments}

We are grateful to the Canadian Brain Tissue Bank for generous supplies of white matter from normal and diseased material. With each case, the neuropathological report was provided. We thank Drs. T. Owen and J. McLaurin of the Montreal Neurological Institute, Montreal, Canada for inducing $\mathrm{EAE}$ in $\mathrm{SJL} / \mathrm{J}$ mice, removing the brains and sending them to us.

This work was supported by a grant from the Medical Research Council of Canada (M. A. Moscarello) and by a Studentship from the Multiple Sclerosis Society of Canada (C. Boulias).

\section{References}

1. Elias, S. B. 1987. Oligodendrocyte development and the natural history of multiple sclerosis. Arch. Neurol. 44:1294-1299.
2. Ellison, G. W. 1989. Multiple sclerosis: why? Biomed. \& Pharmacother. 43:327-333.

3. Young, P. R., W. R. Snyder, D. A. Vacante, G. C. Waikus, A. P. Zygas, F Grynspan, C. Charunatilake, and D. H. Wilson. 1988. Acid instability of myelin: a model for myelin degeneration in multiple sclerosis. Med. Hypotheses. 26:3137.

4. McDonald, W. I. 1986. The mystery of the origin of multiple sclerosis. $J$. Neurol. Neurosurg. Psychiatry. 49:113-123.

5. Julien, J., and X. Ferrer. 1989. Multiple sclerosis: an overview. Biomed. \& Pharmacother. 43:335-346.

6. Roth, H. S., K. E. Kronquist, N. Kerlero de Rosbo, B. F. Crandall, and A. T. Campagnoni. 1987. Evidence for the expression of four myelin basic protein variants in the developing human spinal cord through cDNA cloning. J. Neurosci. Res. 17:321-328.

7. Deibler, G. E., H. C. Krutsch, and M. W. Kies. 1986. A new form of myelin basic protein found in human brain. J. Neurochem. 47:1219-1225.

8. Kerlero de Rosbo, N., P. R. Carnegie, C. C. A. Bernard, and D. S. Linthicum. 1984. Detection of various forms of brain myelin basic protein in vertebrates by immunoblotting. Neurochem. Res. 9:1359-1369.

9. Newcombe, J., P. Glynn, and M. L. Cuzner. 1982. The immunological identification of brain proteins on cellulose nitrate in human demyelinating disease. $J$. Neurochem. 38:267-274.

10. Roth, H. J., K. Kronquist, P. J. Pretorius, B. F. Crandall, and A. T. Campagnoni. 1986. Isolation and characterization of a cDNA coding for a novel human $17.3 \mathrm{kDa}$ myelin basic protein variant. J. Neurosci. Res. 16:277-238.

11. Kamholz, J., F. de Ferra, C. Puckett, and R. Lazzarini. 1986. Identification of three forms of human myelin basic protein by cDNA cloning. Proc. Natl. Acad. Sci. USA. 83:4962-4966.

12. Fannon, A. M., and M. A. Moscarello. 1991. Characterization of myelin basic protein charge isomers from adult mouse brain. NeuroReport. 2:135-138.

13. Deibler, G. E., R. E. Martenson, A. J. Kramer, M. W. Kies, and E. Miyamoto. 1975. The contribution of phosphorylation and loss of carboxy terminal arginine to the microheterogeneity of myelin basic protein. J. Biol. Chem. 250:7931-7938.

14. Chou, F. C-H., J. C-H. Chou, R. Shapira, and R. F. Kibler. 1976. Basis of microheterogeneity of myelin basic protein. J. Biol. Chem. 251:2671-2679.

15. Chou, F. C-H., J. C-H. Chou, R. Shapira, and R. F. Kibler. 1977. Modification of myelin basic protein which occurs during its isolation. J. Neurochem. 28:10511059.

16. Cheifetz, S., M. A. Moscarello, and C. M. Deber. 1984. NMR investigation of the charge isomers of bovine myelin basic protein. Arch. Biochem. Biophys. 233:151-160.

17. Wood, D. D., and M. A. Moscarello. 1989. The isolation, characterization and lipid-aggregating properties of a citrulline containing myelin basic protein. J. Biol. Chem. 264:5121-5127.

18. Moscarello, M. A., G. W. Brady, D. B. Fein, D. D. Wood, and T. F. Cruz. 1986. The role of charge microheterogeneity of basic protein in the formation and maintenance of the multilayered structure of myelin: a possible role in multiple sclerosis. J. Neurosci. Res. 15:87-99.

19. McLaurin, J., C. A. Ackerley, and M. A. Moscarello. 1993. Localization of basic protein in human myelin. J. Neurosci. Res. 35:618-628.

20. Lowden, J. A., M. A. Moscarello, and R. Morecki. 1966. Isolation and characterization of an acid-soluble protein from myelin. Can. J. Biochem. 44:567577.

21. Laemmli, U. K. 1970. Cleavage of structural proteins during assembly of the head of bacteriophage T4. Nature (Lond.). 227:680-685.

22. Martenson, R. E., and M. K. Gaitonde. 1969. Electrophoretic analysis of the highly basic proteins of the rat brain fractions which induces experimental allergic encephalomyelitis. J. Neurochem. 16:333-347.

23. Moscarello, M. A., H. Pang, C. R. Pace-Asciak, and D. D. Wood. 1992. The N-terminus of human myelin basic protein consists of $C_{2}, C_{4}, C_{6}$ and $C_{8}$ alkyl carboxylic acids. J. Biol. Chem. 267:9779-9782.

24. Griffith, G. 1983. Immunocytochemistry using thawed frozen sections. In The Science of Biological Specimen Preparation for Electron Microscopy and Microanalysis. J. P. Revel, T. Barnord, and G. H. Haggis, editors. Scanning Electron Microscopy Inc., AMF O'Hare, IL. 153-159.

25. Chia, L. S., J. E. Thompson, and M. A. Moscarello. 1984. Changes in lipid phase behaviour in human myelin during maturation and aging. FEBS (Fed. Eur. Biochem. Soc.) Letts. 157:155-158.

26. Chia, L. S., J. E. Thompson, and M. A. Moscarello. 1984. Alteration in lipid phase behaviour in multiple sclerosis myelin revealed by wide angle $\mathrm{x}$-ray diffraction. Proc. Nat. Acad. Sci. USA. 81:1871-1874.

27. Hashim, G., and E. H. Eylar. 1969. The structure of the terminal regions of the encephalitogenic basic protein from bovine myelin. Arch. Biochem. Biophys. 135:324-333.

28. Carnegie, P. R. 1969. N-terminal sequence of an encephalitogenic protein from human myelin. Biochem. J. 111:240-242.

29. McLaurin, J., G. Hashim, and M. A. Moscarello. 1992. An antibody specific for component 8 of myelin basic protein from normal brain reacts strongly with component 8 from multiple sclerosis brain. J. Neurochem. 59:1414-1420.

30. Lamensa, J. W. E., and M. A. Moscarello. 1993. Deimination of human 
myelin basic protein by a peptidylarginine deiminase from bovine brain. J. Neurochem. 61:987-996.

31. Fannon, A., and M. A. Moscarello. 1990. Myelin basic protein (MBP) is affected by reduced synthesis of myelin proteolipid protein (PLP) in the jimpy mouse. Biochem. J. 268:105-110.

32. Wiggins, R. C., and G. N. Fuller. 1978. Early post natal starvation causes lasting brain hypomyelination. J. Neurochem. 30:1231-1237.

33. Svennerholm, L., and M. T. Vanier. 1973. The distribution of lipids in the human nervous system. III. Fatty acid composition of phosphoglycerides of human foetal and infant brain. Brain Res. 50:341-351.

34. Svennerholm, L., and M. T. Vanier. 1973. The distribution of lipids in the human nervous system. IV. Fatty acid composition of major sphingolipids of human infant brain. Brain Res. 55:413-423.

35. Brady, G. W., D. B. Fein, D. D. Wood, and M. A. Moscarello. 1985. The role of charge microheterogeneity of human myelin basic protein in the formation of phosphatidylglycerol multilayers. Biochem. Biophys. Res. Commun. 126:11611165.

36. Campagnoni, A. T., T. M. Pribyl, C. W. Campagnoni, F. Kamp, K. AmurUmarjee, C. F. Landry, V. W. Handley, S. L. Newman, B. Garbay, and K. Kitamura. 1993. Structure and developmental regulation of golli-MBP, a 105 kilobase gene that encompasses the myelin basic protein gene and is expressed in cells in the oligodendrocyte lineage in the brain. J. Biol. Chem. 268:4930-4938.

37. Haas, S., J. Gordon, and K. Khalili. 1993. A developmentally regulated DNA binding protein from mouse brain stimulates myelin basic protein gene expression. Mol. Cell. Biol. 13:3103-3112.

38. Philips, J. T. 1993. Regression analysis of multiple sclerosis population data predicts multigenic interaction and minor combined effects of HLA and T cell receptor genes. Neurology. 43:203P.

39. Poser, C. M. 1992. Multiple sclerosis. Observations and reflections-a personal memoir. J. Neurol. Sci. 107:127-140. 